\title{
Effect of Microbial Inoculation on the Nutritive Value of Grass Silage
}

\author{
DW Rice, BR Harman, MA Hinds
}

Pioneer Hi-Bred International, Inc, Microbial Genetics Division, Johnston, Iowa, USA

The effects of microbial inoculation on the nutritive value of timothy grass was assessed by conducting a digestion study with lambs. A timothy grass sward was harvested June 21, 1994 from a field in Withee, Wisconsin. The grass was cut with a self propelled mower conditioner then immediately chopped with a forage harvester to a theoretical length of approximately $16 \mathrm{~mm}$. The forage was packed into $208 \mathrm{~L}$ barrels, $58 \mathrm{~cm}$ in diameter by $86 \mathrm{~cm}$ in height. The barrels were double lined with plastic bags. Ten silos (barrels) were filled per treatment, each plastic bag was tied shut with light gauge wire immediately after packing. The treatments were control and Pioneer ${ }^{(\oplus)}$ brand 1188 Silage Inoculant (1188). The inoculant was applied in the granular form at the recommended rate to supply $1 \times 10^{5}$ colony forming units/g of forage. The inoculant was mixed with the forage by placing approximately $114 \mathrm{~kg}$ of forage material on a $5 \mathrm{~m} \times 5 \mathrm{~m}$ piece of plastic, adding the inoculant, then mixing the forage with a shovel. The silos were filled one at a time by treatment. The initial forage dry matters at ensiling were $26.7 \%$ and $26.6 \%$ for the control and 1188 treatments, respectively. No differences $(P>0.05)$ were observed between treatments for the compositional parameters measured.

The first pair of silos were opened 111 days after ensiling to background the lambs to the experimental diet before the initiation of the experiment. Samples were taken from each silo as they were fed out and composited by treatment. The silage dry matters were $27.8 \%$ and $28.1 \%$ for the control and 1188 treatments, respectively. Twelve wether lambs, with an average body weight of $30.2 \mathrm{~kg}$, were used in an intake/digestion study to evaluate the nutritive value of the timothy grass silage. The lambs were randomly allotted to treatment by weight. The lambs were placed into metabolism crates with access to water and salt/mineral blocks at all times. The ration consisted of $82 \%$ grass silage, $9 \%$ shelled corn, $8 \%$ protein supplement, and $1 \%$ mineral supplement on a dry matter basis and was fed twice daily. A voluntary intake study was conducted for nine days with feeding levels adjusted daily to provide approximately $10 \%$ refusal, intake was then cut to $90 \%$ of the established voluntary intake of each lamb of the seven day collection period running from days 10-16. Feces and urines were collected days $12-16$ of the study. Voluntary dry matter intake (DMI) was greater $(P \leq 0.05)$ for the control lambs $(874.8 \mathrm{~g} / \mathrm{d})$ versus 1188 lambs $(830.4 \mathrm{~g} / \mathrm{d})$. Lamb metabolic weight and DMI were used as covariates in the analysis of the digestion coefficients to adjust for differences in lamb size and intake. Microbial inoculation of the timothy grass at ensiling resulted in an increase $(P \leq 0.05)$ in the apparent digestibility of NDF and hemicellulose over the control treatment.

Digestion Coefficients

\begin{tabular}{lccc} 
Parameter & Control & 1188 & Standard error \\
\hline Dry matter (\%) & 57.2 & 60.0 & 0.92 \\
Nitrogen (\%) & 69.1 & 69.9 & 0.79 \\
Neutral detergent fiber (\%) & 46.6 & $52.9^{*}$ & 1.24 \\
Acid detergent fiber (\%) & 48.3 & 50.8 & 1.07 \\
Hemicellulose (\%) & 43.6 & $56.3^{\star}$ & 2.28
\end{tabular}

* Different from control $(P \leq 0.05)$. 